DOI: $10.4274 /$ tpa.46.29

\title{
Akran istismarı
}

Peer abuse

\author{
Müjgan Alikaşifoğlu \\ Istanbul Üniversitesi Cerrahpaşa Tıp Fakültesi, Çocuk Sağlı̆ı ve Hastalıkları Anabilim Dalı, Adolesan Bilim Dalı, İstanbul, Türkiye
}

\section{Özet}

Akran istismarı sıklıkla kabadayılık/zorbalık davranışları şeklinde karşımıza çıkmaktadır. Kabadayılık/zorbalığın yaygın olarak kabul edilen tanımlaması Dan Olweus tarafından yapılmıştır. Olweus'a göre kabadayılık/zorbalık saldırgan bir davranıştır. Güç dengesizliği olan ilişkilerde gözlenir. Karşı tarafa zarar ya da sıkıntı vermeye yöneliktir ve zaman içerisinde tekrarlanır. Kabadayılık/ zorbalığın çocuk istismarı, aile içi şiddet gibi diğer istismar tipleriyle pek çok ortak özelliği vardır. Kabadaylık/zorbalık fiziksel, sözel ya da diğer direkt ya da indirekt yöntemler kullanılarak gerçekleştirilebilir. Bu davranışlar erkeklerde daha sık görülmekte ve erkekler erkekler tarafından hedef seçilirken, kızlar hem erkekler hem de kızlar tarafından hedef seçilmektedir. Kabadayılığa/zorbalığa uğrama yaşla azalırken, kabadayılık/ zorbalık yapma yaşla belirgin olarak değişmemektedir. Araştırmalar kabadayılık/zorbalık yapma ve/veya kabadayılığa/ zorbalığa uğrama ile bireysel ve çevresel pek çok etken arasında ilişki olduğunu göstermiştir. Kabadayılığa/zorbalığa uğramak çocukların fiziksel sağlığını, psikososyal ve akademik yaşantılarını etkileyebilmektedir. Hekimler kabadayılık/zorbalığa uğrama riski olan çocukları saptayarak, aileleri ile sorunu tartışarak, bu çocukları eşlik eden psikiyatrik sorunlar açısından tarayarak ve kabadayılığı/zorbalığı önleme ve müdahale programlarını destekleyerek bu sorunun çözümlenmesinde rol oynayabilirler. (Türk Ped Arş 2011; 46 Özel Sayl: 31-4)

Anahtar sözcükler: Akran istismarı, fiziksel sağlık, ruhsal sağlık, önleme

\section{Summary}

Peer abuse is commonly seen as bullying behaviors. The most common definition of bullying used in the literature was formulated by Dan Olweus. According to Olweus, bullying is an aggressive behavior that: (a) is intended to cause harm or distress, (b) occurs repeatedly over time, and (c) occurs in a relationship in which there is an imbalance of power. Peer abuse shares many characteristics with other types of abuse, namely child maltreatment and domestic violence. Bullying behaviors may be physical, verbal, non-physical and non-verbal, and may be direct and indirect. Boys are more likely than girls to report bullying behaviors. While boys are bullied by only boys, girls are bullied by both girls and boys. Although, being bullied decreases with age, bullying others does not show the same pattern. Researches identified many individual and environmental factors that place children and adolescents at risk for bullying others and being bullied. Bullying may effect the physical and psychological health and academic work of children who are targeted. Physicians have important roles in identifying at-risk children, screening for psychiatric comorbidities, counseling families about the problem, and advocating for bullying prevention in their communities. (Turk Arch Ped 2011; 46 Suppl: 31-4)

Key words: Peer abuse, physical health, mental health, intervention

\section{Giriş}

Akran istismarı sıklıkla kabadayılık/zorbalık davranışları şeklinde karşımıza çıkmaktadır. Çocukluk çağı boyunca gözlenen kabadayılık/ zorbalık davranışları uzun yıllar normal gelişimin bir parçası olarak kabul edilmiştir. Ancak, son yıllarda yapılan araştırmalar bu davranışların, özellikle okul çocukları ve ergenler arasında madde kullanımı ve erken yaşta cinsel ilişkiye girme gibi davranışlardan daha büyük bir sorun olduğunu göstermiştir (1).

Yazışma Adresi/Address for Correspondence: Dr. Müjgan Alikaşifoğlu,

İstanbul Üniversitesi Cerrahpaşa Tıp Fakültesi, Çocuk Sağlığı ve Hastalıkları Anabilim Dalı, 34303 Fatih, İstanbul, Türkiye E-posta: kasif@istanbul.edu.tr 


\section{Tanım}

Kabadayılık/zorbalık için yaygın olarak kabul gören tanımlama Dan Olweus tarafından yapılmıştır. Olweus'a göre kabadayılık/ zorbalık saldırgan bir davranıştır $(2,3)$. Güç dengesizliği olan ilişkilerde gözlenir. Karşı tarafa zarar ya da sıkıntı vermeye yöneliktir ve zaman içerisinde tekrarlanır. Kabadayılık/zorbalık arkadaşın arkadaşı istismarıdır ve çocuk istismarı ve aile içi şiddet gibi diğer istismar tipleriyle pek çok ortak özelliği vardır. Kabadayılık/zorbalık fiziksel, sözel ya da diğer direkt ya da indirekt yollar kullanılarak gerçekleştirilebilir (Tablo 1).

\section{Epidemiyoloji}

Ülkemizde yapılan araştırmaların sonuçları kabadayılık/ zorbalık davranışlarının yaygınlığını göstermesi açısından önemlidir. İstanbul'da liseye devam etmekte olan ergenlerin $\% 9,2$ 'si okulda son yarı yılda arkadaşlarına en az bir kez kabadaylık/zorbalık yaptıklarını, \%22'si kabadayılık/zorbalığa uğradıklarını ve \%9,4'ü ise hem kabadayılık/zorbalık yaptıklarını hem de kabadayılığa/zorbalığa uğradıklarını bildirmişlerdir (4). Ankara'da yapılan bir araştırmada ise 692 öğrencinin hepsi kabadayılığa/zorbalığa uğradığını bildirmiştir (5). 2005/2006 yllında Türkiye genelinde ilk ve ortaöğretim öğrencileri arasında yaptığımız bir araşıırmada öğrencilerin \%65,2'si son 1-2 ay içerisinde zorbalığa uğradıklarını, \%15,8'i ( $n=841)$ ise haftada en az bir kez zorbalığa uğradıklarını belirtmişlerdir (6).

Pek çok araştırma okullarda sınıf büyüdükçe kabadayilık/ zorbalığa uğrama sıklığının azaldığını göstermiştir (4,7-9). Kabadaylık/zorbalık davranışları açısından bazı ilginç cinsiyet farklılıkları gözlenmektedir (1,4,10,11-18). Öğrencilerin bildirimine dayanan çalışmalarda erkekler kızlardan daha çok kabadayılık/zorbalık yaptıklarını bildirmektedirler $(1,4,10,11-16)$. Kabadayılığa/zorbalığa uğrama sıklığına baktığımızda ise cinsiyet farkı çok belirgin değildir (5,10,11-14,17-19). Kabadayılığa/ zorbalığa uğrama ve cinsiyet ilişkisi ile ilgili tek kesin bulgu kızların hem erkekler hem de kızlar tarafından, erkeklerin ise yalnızca erkekler tarafından kurban olarak seçilmeleridir (2).
Kızların ve erkeklerin maruz kaldıkları kabadayılık/zorbalık davranışlarının tipleri arasında da farklılıklar vardır. Erkekler kızlara göre daha fazla oranda fiziksel olarak kabadayllığa/ zorbalı̆̆a uğrama bildirirken, kızlar erkeklere göre daha fazla oranda haklarında dedikodu çıkarıması ya da cinsellikle ilgili sözler kullanılarak sataşılması şeklinde indirekt davranışlara maruz kaldıklarını bildirmişlerdir $(17,19)$.

Kızların kızlara uyguladığı kabadayılı/zorbalık davranışları incelendiğinde, kızların birbirlerini erkeklerin erkeklere uyguladığından daha fazla oranda yalnız bırakma (sosyal izolasyon) şeklinde kabadayılık/zorbalık davranışında bulunduklarını saptanmıştır (2).

\section{Kabadayılığa/zorbalığa uğrayan çocuklar}

Kabadayılığa/zorbalığa uğrayan çocuklar literatürde 2 grupta toplanmaktadır. Birinci gruba "pasif olarak kabadayılığa/zorbalığa uğrayanlar", ikinci gruba ise "aktif olarak kabadayılığa/ zorbalığa uğrayanlar" girmektedir (2). İkinci grubu "Provokatif kurbanlar" ya da "Hem kabadayllik/ zorbalık yapanlar hem de kabadayılığa/zorbalığa uğrayanlar" olarak adlandıranlar da vardır.

\section{Pasif olarak kabadayılığa/zorbalığa uğrayan çocukların özellikleri}

Sadece kabadayılığa/zorbalığa uğrayanlar tedirgin, duyarl, arkadaş grupları içinde kendini ispat etme güçǚ̆ü yaşayan, öz saygıları eksik ve endişeli çocuklardır (11,12,20-23). Genel olarak arkadaş gruplarından dışlanırlar ve yalnızlık hissederler $(20,24,25)$. Çocuk inmali ve istismarına uğramış çocukların kabadayılığa/zorbalığa uğrama riski de yüksek bulunmuştur $(2,26)$. Kabadayllığa/zorbalığa uğramanın sosyoekonomik düzey ile ilişkisi tartışmalıdır (4,9,12,27-29). Özürlü çocukların da kabadayılığa/zorbalığa uğrama açısından kolay birer hedef olabildikleri saptanmışıı (2).

\section{Hem kabadayılık/zorbalık yapan hem de} kabadayılığa/zorbalı̆̆a uğrayan çocukların özellikleri

Bu gruba giren çocuklar sadece kabadayılığa/zorbalığa uğrayan çocuklarla pek çok ortak özellik gösterirler. Ayrıca, hiperaktif ve konsantrasyon güçlüğü yaşayan çocuklardır $(2,7,13,14,30,31)$. Bu çocuklar kabadayılık/zorbalık davranışlarına karışan çocuklar içerisinde dikkat çeken

Tablo 1. Kabadayılık / zorbalığın yaygın olarak görülen tipleri

\begin{tabular}{|c|c|c|}
\hline & Direkt kabadayılık / zorbalık & İndirekt kabadayılık / zorbalık \\
\hline Sözel & Ad takma, alay etme, kızdırma, eziyet etme & Dedikodu çıkartma \\
\hline Fiziksel & İtmek, tekmelemek, eşyalarını çalmak ya da zarar vermek & $\begin{array}{l}\text { Kendi amacı için bir arkadaşını başkasına(larına) } \\
\text { sataşmak üzere kışkırtmak }\end{array}$ \\
\hline Fiziksel/sözel olmayan & Tehdit etmek, müstehcen hareketler yapmak & $\begin{array}{l}\text { Bir gruptan birini(lerini) dışlamak, arkadaşlıkları } \\
\text { yönlendirmek, e-posta ile tehdit etmek }\end{array}$ \\
\hline
\end{tabular}


grubu oluşturmaktadırlar; çünkü hem kabadayılığa/zorbalığa uğrayanların gösterdiği duygusal sorunları, hem de kabadayılık/zorbalık yapanların gösterdiği davranışsal sorunları gösterirler $(4,8,13,14,30,31)$. Bu çocukların hem arkadaş ilişkilerinde sorunlar yaşadıkları ve yalnız kaldıkları, hem de akademik başarısızlık, sigara ve alkol kullanımı gibi riskli davranışları diğer çocuklardan daha fazla gösterdikleri saptanmıştır $(19,32)$.

\section{Hekimlerinin rolü}

Hekimler özellikle hem kabadayılık/zorbalık yapan hem de kabadayılığa/zorbalığa uğrayan çocukları saptayabilmelidirler; çünkü bu çocuklar psikolojik ya da psikiyatrik sorunların en fazla görüldüğü çocuklardır $(4,7,13,14,30,31)$.

Bir çocuğun kabadayılık/zorbalık yaptığını ya da kabadayılığa/zorbalığa uğradığını saptayabilecek bir ölçme yöntemi bulunmamaktadır. Ancak, bir çocuk aşağıda belirtilen özelliklerden bir ya da bir kaçını taşıyorsa hekimler çocuğu kabadayılığa/zorbalığa uğramış olma riski açısından değerlendirmek üzere izlemelidirler $(2,33)$.

1- Okuldan eve eşyaları kaybolmuş ya da zarar görmüş olarak dönen çocuklar

2- Bedeninde açıklanamayan çürükler, kesikler ya da çizikler olan çocuklar

3- Arkadaşı olmayan ya da az sayıda arkadaşı olan ve arkadaş ilişkilerinde sorun yaşayan çocuklar

4- Okula gitmekten korkan çocuklar

5- Okul ödevleri ile ilgilenmeyen ve akademik başarısı düşük çocuklar

6- Açıklanamayan psikosomatik yakınmaları olan çocuklar

7- Gece korkuları olan ya da uyku bozukluğu gözlenen çocuklar

8- Üzgün, depresif görünen ve intihar düşüncesi olan çocuklar

9- Gergin görünen öz güveni eksik çocuklar

10- Sessiz, duyarlı ve pasif çocuklar

\section{Sonuç}

Hekimler akran istismarını bir sağlık sorunu olarak kabul edip, çocukları bu konuda değerlendirmeye ve risk altındaki çocukları saptamaya ve desteklemeye ilgi duyarlarsa, bu sorunun çözümünde çok önemli bir rol oynayabilirler.

Akran istismarına karışan çocuklara yardım etmek için gösterilen küçük bir çabanın etkisi büyük olabilir ve böylece belki de çocuğun yaşamı boyunca yer alacağı sosyal ortamlarda benzer davranışlar sergilemesi ya da benzer davranışlara maruz kalmasını engelleyecek şekilde ilişkiler kurması sağlanabilir.

\section{Kaynaklar}

1. Currie C, Roberts C, Morgan A et al. Young People's Health in Context: International report from the HBSC 2001/2002 survey. WHO policy series: Health policy for children and adolescents Issue 4. Copenhagen, WHO Regional Office for Europe, 2004.

2. Fleming $\mathrm{M}$, Towey $\mathrm{K}$ (eds.). Educational forum on adolescent health. Youth bullying, Chicago: American Medical Association, 2002.

3. Olweus D. Bullying at school. Basic facts and effects of a school based intervention program. J Child Psychol Psychiatry 1994; 35: 1171- 90. (Abstract)

4. Alikasifoglu M, Erginöz E, Ercan $\mathrm{O}$ et al. Bullying behaviours and psychosocial health: results from a cross-sectional survey among high school students in İstanbul, Turkey. Eur J Pediatr 2007; 166: 1253-60. (Abstract) / (PDF)

5. Kepenekci- Karaman Y, Cinkir S. Bullying among Turkish high school students. Child Abuse Negl 2006; 30: 193-204. (Abstract) / (Full Text) / (PDF)

6. Okul çağı çocuklarının sağlık davranışı araştırması Türkiye 2006 raporu. İstanbul: Galenos yayın evi, 2009:74.

7. Kristensen SM, Smith PK. The use of coping strategies by Danish children classed as bullies, victims, bully/victims, and not involved, in response to different (hypothetical) types of bullying. Scand J Psychol 2003; 44: 479-88. (Abstract) / (Full Text) / (PDF)

8. Salmon G, James A, Smith DM. Bullying in schools: self reported anxiety, depression, and self esteem in secondary school children. BMJ 1998; 317: 924-5. (Abstract)

9. Smith PK, Madsen KC, Moody JC. What causes the age decline in reports of being bullied at school? Towards a developmental analyses of risk of being bullied. Educ Research 1999; 41: 267-85. (Abstract) / (PDF)

10. Craig WM, Pepler DJ. Identifying and targeting risk for involvement in bullying and victimization. Can $\mathrm{J}$ Psychiatr 2003; 48: 577-82.

11. Forero R, McLellan L, Rissel C, et al. Bullying behavior and psychosocial health among school students in New South Wales, Australia: cross sectional survey. BMJ 1999; 319: 344-8. (Abstract)

12. Gofin R, Palti H, Gordon L. Bullying in Jerusalem schools: victims and perpetrators. Public Health 2002;116: 173-8. (Abstract) / (Full Text) / (PDF)

13. Juvonen J, Graham S, Schuster MA. Bullying among young adolescents: The strong, the weak, and the troubled. Pediatrics 2003; 112: 1231-7. (Abstract) / (PDF)

14. Kaltiala-Heino R, Rimpelä $M$, Rantanen $P$, Rimpelä A. Bullying at school-an indicator of adolescents at risk for mental disorders. J Adolesc 2000; 23: 661-74. (Abstract) / (PDF)

15. Kim YS, Koh YJ, Leventhal B. School bullying and suicidal risk in Korean middle school students. Pediatrics 2005; 115: 357-63. (Abstract) / (PDF)

16. Seals D, Young J. Bullying and victimization: prevalence and relationship to gender, grade level, ethnicity, self-esteem, and depression. Adolescence 2003; 38: 735-47. (Abstract)

17. Baldry AC, Farrington DP. Types of bullying among Italian school children. J Adolesc 1999; 22: 423-6. (Abstract) / (PDF)

18. Lopes Neto AA. Bullying-aggressive behavior among students. J Pediatr 2005; 81: 164-72. (Abstract) / (PDF)

19. Nansel TR, Overpeck M, Pilla RS, et al. Bullying behavior among US youths: Prevalence and association with psychosocial adjustment. JAMA 2001; 285: 2094-100. (Abstract)

20. Muscari ME. Sticks and stones: The NP's role with bullies and victims. J Pediatr Health Care 2002; 16: 22-8. (Abstract) / (Full Text) / (PDF) 
21. Janssen I, Craig WM, Boyce WF, Pickett W. Associations between overweight and obesity with bullying behaviors in school-aged children. Pediatrics 2004; 113: 1187-94. (Abstract) / (Full Text) / (PDF)

22. Rigby K. Consequences of bullying in schools. Can J Psychiatr 2003; 48: 583-90. (Abstract)

23. SMITH Peter K, TALAMELLI Lorenzo, COWIE Helen, NAYLOR Paul, CHAUHAN Preeti. Profiles of non-victims, escaped victims, continuing victims and new victims of school bullying. $\mathrm{Br} \mathrm{J}$ Educ Psychol 2004; 74: 565-81. (Abstract)

24. Eslea M, Menesini E, Morita $Y$ et al. Friendship and loneliness among bullies and victims: Data from seven countries. Aggr Behav 2004; 30: 71-83. (Abstract) / (PDF)

25. Kaltiala-Heino $R$, Rimpela $M$, Marttunen $M$, Rimpela $A$, Rantanen P. Bullying, depression, and suicidal ideation in Finish adolescents: school survey. BMJ 1999; 319: 348-51. (Abstract) / (Full Text) / (PDF)

26. Shields A, Cicchetti D. Parental maltreatement and emotion dysregulation as risk factors for bullying and victimisation in middle childhood. J Clin Child Psychol 2001; 30: 349-63. (Abstract)
27. Kumpulainen K, Rasanen E, Henttonen I. Children involved in bullying: Psychosocial disturbance and the persistence of the involvement. Child Abuse Negl 1999; 23: 1253-62. (Abstract) / (Full Text) / (PDF)

28. Sourander A, Helstelä L, Helenius H, Piha J. Persistance of bullying from childhood to adolescence-a longitudinal 8 year follow-up study. Child abuse Negl. 2000; 24: 873-81. (Abstract) / (Full Text) / (PDF)

29. Wolke D, Woods S, Stanford K, Schulz H. Bullying and victimization of primary school children in England and Germany: prevalence and school factors. Br J Psychol. 2001; 92: 673-96. (Abstract)

30. Ivarsson T, Broberg AG, Arvidsson T, Gillberg C. Bullying in adolescence : Psychiatric problems in victims and bullies as measured by the Youth Self Report (YSR) and the Depression SelfRating Scale (DSRS). Nord J Psychiatry 2005; 59: 365-73. (Abstract) / (PDF)

31. Kumpulainen K, Rasanen E, Henttonen I et al. Bullying and psychiatric symptoms among elementary school-age children. Child Abuse Negl 1998; 22: 705-17. (Abstract) / (Full Text) / (PDF)

32. Shwartz D. Subtypes of victims and aggressors in children's peer groups. J Abnorm Child Psychol 2000; 28: 181-92. (Abstract) / (PDF) 